\title{
Nodulação e produtividade de Vigna unguiculata (L.) Walp. por cepas de rizóbio em Bom Jesus, PI $^{1}$
}

\author{
Yield and nodulation of Vigna unguiculata (L.) Walp. inoculated with rhizobia \\ strains in Bom Jesus, PI
}

\author{
Elaine Martins Costa ${ }^{2}$, Rafaela Simão Abrahão Nóbrega ${ }^{3 *}$, Linnajara de Vasconcelos Martins ${ }^{4}$, Francisco Hélcio \\ Canuto Amaral ${ }^{4}$ e Fátima Maria de Souza Moreira ${ }^{5}$
}

\begin{abstract}
Resumo - Objetivou-se avaliar a resposta de Vigna unguiculata (L.) Walp. cv. "BR 17 Gurguéia" à inoculação com duas cepas isoladas de solos de mineração de bauxita em reabilitação: UFLA 3-164 e UFLA 3-155 e três cepas INPA 03 11B (BR 3301); UFLA 0384 (BR 3302) e BR 3267 (SEMIA 6462), autorizadas pelo MAPA como inoculantes para a cultura do feijão-caupi. O experimento foi conduzido em campo na Universidade Federal do Piaú, Campus Professora Cinobelina Elvas, Bom Jesus, PI. Utilizou-se o delineamento experimental em blocos casualizados com sete tratamentos e com seis repetições, sendo cinco cepas citadas e dois controles não inoculados, um com N-mineral (70 kg ha-1 $\mathrm{de} \mathrm{N})$ e outra sem $\mathrm{N}$ mineral. Foram avaliados a nodulação (número e massa seca de nódulos), o crescimento (massa seca da parte aérea), o rendimento de grãos e o teor e acúmulo de nitrogênio na parte aérea e nos grãos, além da eficiência relativa. A inoculação das sementes com as cepas de bactérias diazotróficas simbióticas resultou em rendimentos de grãos equivalente à testemunha adubada com nitrogênio mineral. A cepa em fase de teste, UFLA 3-155 apresentou rendimento de grãos igual à cepa recomendada INPA 03 11B (BR 3301), podendo também ser testada em outras regiões brasileiras. Entre as cepas aprovadas pelo MAPA a INPA 03 11B (BR 3301) apresentou a maior produção de grãos.
\end{abstract}

Palavras-chave - Bradyrhizobium. Fixação biológica de $\mathrm{N}_{2}$. Leguminosas.

\begin{abstract}
It evaluates the effect of inoculation with two rhizobia strains isolated from soils under rehabilitation after bauxite mining: UFLA 3-164 and UFLA 3-155, compared to inoculation with strains INPA 03 11B (BR 3301); UFLA 0384 (BR 3302) and BR 3267 (SEMIA 6462), officially authorized as inoculant to cowpea by MAPA, in Vigna unguiculata (L.) Walp cv. "BR 17 Gurgueia". The experiment was carried out at the "Universidade Federal do Piauí, Campus Professora Cinobelina Elvas, Bom Jesus, PI,' in a randomized block design, white seven treatments and six replications. Treatments were the five strains and two controls: one receiving mineral $\mathrm{N}\left(70 \mathrm{~kg} \mathrm{ha}^{-1} \mathrm{de} \mathrm{N}\right)$ and the other an absolute control. Nodule number and dry matter weight, shoot dry matter weight, grain yields and N-content both in shoots and grain were evaluated. The inoculation of the seeds with diazotrophic symbiotic bacterial strains resulted in the improvement of yields equivalent and/ or superior to the control receiving mineral nitrogen. The strain UFLA 3-155 has presented a grain yield similar to one of MAPA recommended strains, INPA 03 11B (BR 3301) and can also be tested in other brazilian regions. Among the strains recommended by MAPA, the INPA 03 11B (BR 3301) produced the higher yields.
\end{abstract}

Key words - Brandyrhizobium. Fixation of $\mathrm{N}_{2}$. Legumes.

\footnotetext{
* Autor para correspondência

${ }^{1}$ Recebido para publicação em 21/04/2010; aprovado em 09/10/2010

Pesquisa finaciada pelo CNPq, corresponde ao trabalho de iniciação científica do primeiro autor

${ }^{2}$ Graduanda em Engenharia Agronômica, bolsista do PIBIc/UFPI, Universidade Federal do Piauí, Campus Professora Cinobelina Elvas, Caixa Postal 58, Bom Jesus-PI, Brasil, 64.900-000, elainemartins@hotmail.com

${ }^{3}$ Universidade Federal do Piauí, Campus Professora Cinobelina Elvas, Caixa Postal 58, Bom Jesus-PI, Brasil, 64.900-000, rafaela.nobrega@gmail.com ${ }^{4}$ Graduando (a) em Engenharia Agronômica, bolsista do PIBIc/CNPq, Universidade Federal do Piauí, Campus Professora Cinobelina Elvas, Caixa Postal 58, Bom Jesus-PI, Brasil, 64.900-000, linnajaravasconcelos@hotmail.com, franciscohelcio@ufpi.br

${ }_{5}^{5}$ Pesquisadora e bolsista produtividade do CNPq, Universidade Federal de Lavras, Campus Universitário, Caixa Postal 37, Lavras-MG, Brasil,

35.200-000, fmoreira@ufla.edu.br
} 


\section{Introdução}

No estado do Piauí, o feijão-caupi ocupa lugar de destaque na produção agrícola com área em torno de 200 mil ha em cultivo de primeira safra e 10 mil ha em cultivo de segunda safra, gerando cerca de $210 \mathrm{mil}$ empregos ano ${ }^{-1}$ e uma oferta capaz de alimentar mais de 3 milhões de pessoas (FREIRE FILHO et al., 2007). No entanto, considerando a produtividade, o cenário atual está longe do verificado pela pesquisa, em que a média para o cultivo de primeira safra é em torno de $369 \mathrm{~kg} \mathrm{ha}^{-1}$ para as diferentes microrregiões do Estado com mínimo de 181 e máximo de $880 \mathrm{~kg} \mathrm{ha}^{-1}$, respectivamente, para as microrregiões da Chapada Extremo Sul Piauiense e Alto Parnaíba Piauiense (IBGE, 2006).

Trabalhos desenvolvidos com o feijão-caupi têm demonstrado a obtenção de rendimentos de grãos significativos com utilização de inoculantes de bactérias nodulíferas de leguminosas (BNL) num processo conhecido como fixação biológica de nitrogênio (FBN) (ALMEIDA et al., 2010; LACERDA et al., 2004; MARTINS et al., 2003; SOARES et al., 2006; ZILLI et al., 2006). Lacerda et al. (2004), em ensaio conduzido no município de Perdões, MG, utilizando a cultivar de feijão-caupi BR 14 Mulato verificaram rendimento de grãos de 1.341 e $1.413 \mathrm{~kg} \mathrm{ha}^{-1}$ para o tratamento inoculado com a cepa INPA 03 11B (BR 3301) e testemunha com $\mathrm{N}$ mineral (70 $\mathrm{kg} \mathrm{ha}^{-1}$ de $\mathrm{N}$ fonte uréia), respectivamente. Soares et al. (2006), verificaram aumento no rendimento de grãos do feijão-caupi em Perdões, $M G$, inoculado com as cepas INPA 03 11B (BR 3301) e UFLA 0384 (BR 3302). Estas proporcionaram uma produtividade de 949 e $957 \mathrm{~kg} \mathrm{ha}^{-1}$, respectivamente, sendo esses tratamentos superiores à cepa de referência, BR 2001, que proporcionou uma produtividade de $473 \mathrm{~kg} \mathrm{ha}^{-1}$. Segundo Sousa (2007), a inoculação do feijão-caupi com INPA 03 11B (BR 3301) possibilitou o rendimento de grãos, em ensaio de campo, promovendo um incremento de mais de $35 \%$, comparada à produtividade sem $\mathrm{N}$-mineral e sem inoculante, apresentando-se como alternativa de baixo custo e podendo beneficiar os agricultores do município de Confresa, MT, caso seja adotada.

Apesar dos resultados promissores, sabe-se que bactérias são sensíveis aos distúrbios como os introduzidos pelas práticas agrícolas (DEPRET et al., 2004; FERREIRA et al., 2000; JESUS et al., 2009; LIMA et al, 2009), além de serem afetadas por uma série de fatores bióticos e abióticos (HUNGRIA; VARGAS, 2000). Entre os fatores abióticos, destacamse a acidez do solo e disponibilidade de nutrientes (FERREIRA et al., 2009), como a presença de teores altos de alumínio (ANDRADE et al., 2002) e de cobre trocáveis (SANTOS et al., 2007) e disponibilidade de nitrogênio no solo (GUALTER et al., 2008; VIEIRA et al., 2005). Entre os bióticos pode-se considerar a competição de cepas exóticas com as indígenas, pelos sítios de infecção na raiz que podem ocasionar diminuição na eficiência da fixação de N para a planta, uma vez que os nódulos serão constituídos de cepas de eficiência variável. Considerando também que o feijão-caupi é uma leguminosa promíscua, pois nodula com bactérias de vários gêneros no solo (LIMA et al., 2005; MELLONI et al., 2006), testes de eficiência agronômica em diferentes regiões são imprescindíveis para avaliar a capacidade fixadora de $\mathrm{N}_{2}$ das cepas para cada condição edafo-climática. Além disso, o processo de FBN é também influenciado pelas características genotípicas do macro e microssimbionte, refletindo nas diferentes respostas em relação à faixa hospedeira, especificidade e eficiência simbiótica. A especificidade simbiótica de uma cepa de bactéria fixadora de nitrogênio é representada pela sua habilidade em induzir a nodulação e fixar $\mathrm{N}_{2}$ quando associada a cultivares ou espécies do hospedeiro específico. Assim, para uma mesma espécie, a eficiência pode depender da cultivar (FRANCO et al., 2002; XAVIER et al., 2006).

O presente trabalho teve por objetivo testar a eficiência agronômica de cepas de bactérias diazotróficas simbióticas em fase de seleção bem como as atualmente aprovadas como inoculantes pelo MAPA (Ministério da Agricultura, Pecuária e Abastecimento) para cultura do feijão-caupi (BR 17 Gurguéia), em solo representativo do Pólo de Produção de Bom Jesus, PI.

\section{Material e métodos}

O ensaio foi conduzido em área experimental da Universidade Federal do Piauí, Campus Professora Cinobelina Elvas, Bom Jesus, PI (0904'28' de latitude Sul, 4421'31" de longitude Oeste e com altitude média de $277 \mathrm{~m}$ ) no período de maio a julho de 2009, em um LATOSSOLO AMARELO, textura média, em área sem utilização anterior de qualquer tipo de inoculante. Neste período, o local apresentou temperatura média em torno de $25^{\circ} \mathrm{C}$, com máxima e mínima registradas de 38,2 e de $17^{\circ} \mathrm{C}$, respectivamente.

As características químicas do solo avaliadas na camada de 0 a $0,2 \mathrm{~m}$ foram: $\mathrm{pH}$ em $\mathrm{H}_{2} \mathrm{O}(1: 2,5) 6,5$; $\mathrm{P}$ (Mehlich 1) $12,4 \mathrm{mg} \mathrm{dm}{ }^{-3} ; \mathrm{K}^{+} 0,20 \mathrm{cmol} \mathrm{dm}^{-3} ; \mathrm{Ca}^{2+}$ $1,2 \mathrm{cmol}_{\mathrm{c}} \mathrm{dm}^{-3} ; \mathrm{Mg}^{2+} 0,4 \mathrm{cmol}_{\mathrm{c}} \mathrm{dm}^{-3} ; \mathrm{Al}^{3+} 0 \mathrm{cmol}_{\mathrm{c}} \mathrm{dm}^{-3}$; $\mathrm{H}+\mathrm{Al} 0,9 \mathrm{cmol} \mathrm{dm}^{-3}$; SB $1,8 \mathrm{cmol} \mathrm{dm}^{-3}$; CTC efetiva $1,8 \mathrm{cmol} \mathrm{dm}^{-3}$; CTC potencial $2,7 \mathrm{cmol}_{\mathrm{c}} \mathrm{dm}^{-3} ; \mathrm{m}_{0} \%$; $\mathrm{V} 66,7 \%$; matéria orgânica $0,6 \mathrm{~g} \mathrm{~kg}^{-1} ; \mathrm{Zn}^{2+} 1,2 \mathrm{mg} \mathrm{dm}^{-3}$; $\mathrm{Fe}^{2+} 8,4 \mathrm{mg} \mathrm{dm}^{-3} ; \mathrm{Mn}^{2+} 38,6 \mathrm{mg} \mathrm{dm}^{-3} ; \mathrm{Cu}^{2+} 0,2 \mathrm{mg} \mathrm{dm}^{-3}$; B $0,3 \mathrm{mg} \mathrm{dm}^{-3}$ e S $5,8 \mathrm{mg} \mathrm{dm}^{-3}$. 
O delineamento experimental utilizado foi de blocos casualizados com seis repetições e sete tratamentos (formas de adição de N). Foi utilizada a cultivar de feijão-caupi BR 17 Gurguéia (FREIRE FILHO et al., 2008). Os tratamentos foram constituídos por: três cepas de bactéria fixadora de nitrogênio recomendadas pelo MAPA como inoculante para o feijão-caupi, INPA 03 11B (BR 3301), UFLA 0384 (BR 3302), ambas isoladas de solos da Amazônia e identificadas como pertencentes ao gênero, Bradyrhizobium (SOARES et al., 2006) e BR 3267 (SEMIA 6462), oriunda da coleção de cultura da Embrapa Agrobiologia (RUMJANEK, 2006). Além destas, foram testadas duas cepas em fase de seleção: UFLA 3-164 e UFLA 3-155 (isoladas de solos de mineração de bauxita em reabilitação (MELLONI et al., 2006) e testados com relação à sua eficiência em vasos tipo Leonard com solução nutritiva e vermiculita (MOTTA, 2002) e mais duas testemunhas: uma nitrogenada $\left(70 \mathrm{Kg}_{\mathrm{de}} \mathrm{N} \mathrm{ha}^{-1}\right.$, fonte uréia, conforme recomendação de Freire Filho et al. 2007) e outra sem inoculação e sem N mineral. A adubação nitrogenada foi parcelada em duas doses iguais, uma no plantio e a outra 20 dias após a emergência das plantas.

O solo foi preparado com uma aração e duas gradagens. Todos os tratamentos receberam adubação fosfatada e potássica de $50 \mathrm{~kg} \mathrm{ha}^{-1}$ de $\mathrm{P}_{2} \mathrm{O}_{5}$ e $20 \mathrm{~kg} \mathrm{ha}^{-1}$ de $\mathrm{K}_{2} \mathrm{O}$, usando como fonte o superfosfato simples e o cloreto de potássio, incorporados a $6 \mathrm{~cm}$ de profundidade, conforme a recomendação para a cultura.

O inoculante foi preparado com turfa esterilizada em autoclave, na proporção 3:1 de turfa e cultura em meio YMA semi-sólido na fase log (após cinco dias de crescimento com concentração mínima de $10^{8}$ células $\mathrm{g}^{-1}$ de inoculante). Inocularam-se as sementes na proporção de $500 \mathrm{~g}$ do inoculante por $50 \mathrm{~kg}$ de sementes. A semeadura foi feita imediatamente após a inoculação, semeando-se quatro sementes por cova no espaçamento de 1,0 x 0,20 m. Realizou-se o desbaste aos 15 dias após o plantio, deixandose duas plantas por cova. As parcelas foram constituídas por seis linhas de $6 \mathrm{~m}$ de comprimento, espaçadas em 1,0 m, totalizando $36 \mathrm{~m}^{2}$ de área total e área útil de $12 \mathrm{~m}^{2}$. Durante a condução do ensaio foram realizadas capinas manual e mecânica com a utilização de enxadas, mantendo-se a cultura livre de plantas invasoras.

$\mathrm{Na}$ primeira avaliação realizada por ocasião do florescimento aos 45 dias após o plantio foram coletadas aleatoriamente, dez plantas de cada parcela para avaliação da nodulação: número de nódulos por planta $(\mathrm{NN})$ e matéria fresca e seca de nódulos (MFN e MSN) e parte aérea: produção de matéria seca da parte aérea (MSPA) e eficiência relativa (EFRE). Depois da pesagem, a parte aérea foi moída para a determinação do $\mathrm{N}$ total (TNPA) e acúmulo de $\mathrm{N}$ na parte aérea (ANPA), pelo método semimicro Kjeldahl (LIAO, 1981).
A segunda avaliação foi realizada na colheita, entre os dias 29/06/09 a 13/07/09, em que foram coletadas manualmente as vagens de 100 plantas de cada parcela. Posteriormente, todas as vagens foram secas ao ar e trilhadas para avaliação do número de vagens por planta (NVPL), peso de vagens por planta (PVPL) e rendimento de grãos por hectare (RG). Depois da pesagem os grãos foram moídos para a determinação do teor (TNG) e acúmulo (ANG) do $\mathrm{N}$ total nos grãos pelo método semimicro Kjeldahl (LIAO, 1981).

Para a determinação da produção de matéria seca, a parte aérea foi acondicionada em sacos de papel e depositada em estufa de ar forçado a $65{ }^{\circ} \mathrm{C}$ até atingir peso constante. A eficiência relativa de cada cepa foi calculada utilizando a fórmula de Bergensen et al. (1971). $\mathrm{ER}=(\text { MSPA inoculada })^{*} 100 /($ MSPA da planta adubada com $\mathrm{N}$ mineral). Para avaliar o rendimento de grãos, a sua umidade foi corrigida para $13 \%$ base úmida. $\mathrm{O}$ acúmulo $\mathrm{N}$ nos grãos e na parte aérea foi calculado multiplicando-se o peso da matéria seca da parte aérea (g) ou dos grãos * $(\%$ de $\mathrm{N}) / 100$.

Os dados do ensaio foram submetidos à analise de variância empregando o sistema de análise estatística SISVAR, versão 4.2 (FERREIRA, 2000). Os efeitos dos tratamentos foram comparados pelo teste de Tukey a $5 \%$ de probabilidade. Para as variáveis NN, MFN, MSN e RG os dados foram transformados pela raiz quadrada de $\mathrm{Y}+0,5$.

\section{Resultados e discussão}

$\mathrm{Na}$ primeira avaliação, realizada por ocasião do florescimento, verificou-se efeito significativo das formas de fornecimento de N sobre o NN, MFN, MSN, MSPA, EFRE e ANPA ( 1 e 2).

O NN, MFN e MSN (1) variaram de 4,23 nódulos, 99,50 mg e 24,33 mg (testemunha com $70 \mathrm{~kg}$ $\mathrm{ha}^{-1}$ de N) a 17,43 nódulos planta ${ }^{-1}$ (BR 3267), 670,33 mg planta $^{-1}$ e 127,50 mg planta ${ }^{-1}$ INPA 03 11B (BR 3301) respectivamente, sendo que os tratamentos inoculados apresentaram valores similares entre si e significativamente superior a testemunha com $\mathrm{N}$ mineral. A avaliação do número e matéria seca dos nódulos são alguns dos critérios que fazem parte do protocolo de avaliação da eficiência simbiótica entre rizóbios e leguminosas pelo MAPA. Neste caso, as cepas em fase de seleção (UFLA 3-164 e UFLA 3-155) apresentam boa eficiência para as duas variáveis, com desempenhos similares aos resultados obtidos pelas cepas atualmente recomendadas para cultura UFLA 0384 (BR 3302), INPA 03 11B (BR 3301) e BR 3267 (MAPA, 2006). 
Tabela 1 - Valores médios de número de nódulos por planta (NN), matéria seca (MSN) e fresca (MFN) de nódulos, em função de diferentes formas de fornecimento de $\mathrm{N}$ durante a floração (45 dias após semeadura) da cultura do feijão-caupi

\begin{tabular}{|c|c|c|c|}
\hline \multirow{2}{*}{ Fonte de $\mathrm{N}$} & $\mathrm{NN}$ & MFN & MSN \\
\hline & número planta $^{-1}$ & \multicolumn{2}{|c|}{ 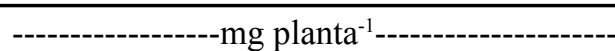 } \\
\hline Test. S/N & $10,83 \mathrm{ab}$ & $438,66 \mathrm{ab}$ & $89,33 \mathrm{ab}$ \\
\hline Test. $\mathrm{C} / \mathrm{N}-70 \mathrm{~kg} \mathrm{ha}^{-1}$ & $4,23 \mathrm{~b}$ & $99,50 \mathrm{~b}$ & $24,33 \mathrm{~b}$ \\
\hline UFLA 3-164 & $11,48 \mathrm{a}$ & $392,83 \mathrm{ab}$ & $87,66 \mathrm{ab}$ \\
\hline UFLA 03-84 (BR 3302) & $12,26 \mathrm{a}$ & $422,33 \mathrm{ab}$ & $92,33 \mathrm{a}$ \\
\hline INPA 03 11B (BR 3301) & $16,45 \mathrm{a}$ & $670,33 \mathrm{a}$ & $127,50 \mathrm{a}$ \\
\hline UFLA 3-155 & $17,00 \mathrm{a}$ & $635,66 \mathrm{a}$ & $103,83 \mathrm{a}$ \\
\hline BR 3267 & $17,43 \mathrm{a}$ & 573,66 a & $119,16 \mathrm{a}$ \\
\hline F (Tratamento) & $6,428^{*}$ & $5,304 *$ & $5,095^{*}$ \\
\hline Tratamento (GL) & 6 & 6 & 6 \\
\hline Bloco (GL) & 5 & 5 & 5 \\
\hline Erro (GL) & 30 & 30 & 30 \\
\hline QMR & 3,27 & 0,06 & 0,00 \\
\hline DMS & 1,30 & 0,19 & 0,04 \\
\hline $\mathrm{CV}(\%)$ & 20,55 & 11,19 & 3,11 \\
\hline
\end{tabular}

ns - não significativo, "Significativo $5 \%$ de probabilidade pelo teste de Tukey, GL= grau de liberdade, QMR = quadrado médio residual, DMS $=$ diferença mínima significativa, $\mathrm{CV}=$ coeficiente de variação. Médias seguidas da mesma letra nas colunas não diferem entre si de acordo com o teste de Tukey a $5 \%$ de probabilidade

A testemunha sem $\mathrm{N}$ mineral apesar de não diferir estatisticamente da testemunha com $\mathrm{N}$ mineral quanto ao NN, MFN e MSN, promoveu maiores valores para essas três variáveis e apresentou comportamento também semelhante aos tratamentos inoculados, evidenciando assim o papel inibidor do N-mineral sobre a nodulação e a presença de populações nativas eficientes em nodular. Não só a densidade de células no inoculante é responsável por promover uma eficiente nodulação, mais também outros eventos como, por exemplo, a interferência dos fatores ambientais e do solo e a capacidade de sobrevivência de cada cepa (DEPRET et al., 2004; FERREIRA et al., 2000; HUNGRIA; VARGAS, 2000).

Soares et al. (2006) trabalhando com a cepa INPA 03 11B (BR 3301) inoculada na cultivar de feijãocaupi BR 14 Mulato, em solo do sul de Minas Gerais, encontraram valores superiores de $\mathrm{NN}$ e $\mathrm{MSN}$, em relação às testemunhas sem $\mathrm{N}$ e com $\mathrm{N}$ mineral. Sousa (2007), estudando o potencial da inoculação com BNL no feijão-caupi em Confresa, $\mathrm{MG}$, obteve 12 nódulos planta $^{-1}$ na testemunha com $70 \mathrm{~kg} \mathrm{ha}^{-1}$ de $\mathrm{N}, 37$ nódulos planta $^{-1}$ na testemunha sem $\mathrm{N}$ mineral e 75 nódulos no tratamento inoculado com a cepa INPA 03 11B (BR 3301). Apesar de apresentar maior $\mathrm{NN}$ em relação ao presente trabalho, a MSN obtida por Sousa (2007) foi menor, variando de $28,90 \mathrm{mg}$ a $74,50 \mathrm{mg}$ planta $^{-1}$, para a testemunha com $\mathrm{N}$ mineral e o tratamento inoculado, respectivamente. Esses resultados diferem dos encontrados por Lacerda et al. (2004), uma vez que o NN e a MSN da testemunha com $\mathrm{N}$ mineral na dose de $70 \mathrm{~kg}$ de $\mathrm{N} \mathrm{ha}^{-1}$ foi semelhante à testemunha sem $\mathrm{N}$ mineral e à maioria dos tratamentos inoculados. Tais diferenças podem ser explicadas pelas populações nativas de BNL, condições edafoclimáticas, etc.

Com relação à MSPA, EFRE e ANPA (2), não houve diferença significativa entre os tratamentos inoculados e a testemunha sem N. Almeida et al. (2010), também avaliando a eficiência das cepas BR 3301 (INPA 03 11B), BR 3302 (UFLA 03 84) e BR 3267 (SEMIA 6462) em experimento de campo em Teresina, PI, verificaram que as produções de MSPA e EFRE foram semelhantes para os tratamentos inoculados e à testemunha sem $\mathrm{N}$ mineral. A falta de diferença entre o tratamento sem $\mathrm{N}$ mineral e os tratamentos inoculados comprova a capacidade da população nativa em estabelecer a simbiose com feijão-caupi, leguminosa considerada promíscua (LIMA et al., 2005; MELLONI et al., 2006) e cultivada anualmente no Pólo de produção Bom Jesus, PI sem a utilização de inoculantes. A cepa UFLA 3-155 (em fase de seleção) destacou-se, promovendo EFRE de 75,4\%, significativamente igual à testemunha nitrogenada. Este resultado é relevante quando o objetivo for a produção de biomassa, seja para adubação verde ou forragem. 
Para a variável TNPA (2) todos os tratamentos inoculados e a testemunha sem $\mathrm{N}$ mineral apresentaramse estatisticamente iguais à testemunha com $\mathrm{N}$ mineral; ressalta-se que estes teores estão acima dos valores indicados por Malavolta et al. (1997) como adequados para a cultura (entre 1,8 a 2,2\%).

Na segunda avaliação, por ocasião da colheita foi verificado efeito significativo das formas de fornecimento de N em relação ao NVPL, PVPL, TNG, ANG e RG (3). Com relação ao NVPL e PVPL, as cepas UFLA 3-155 e INPA 03 11B (BR 3301) destacaram-se das demais, apresentando valores similares à testemunha com $\mathrm{N}$ mineral. A cepa BR 3267 apresentou menores valores para as duas variáveis.

Para a variável TNG (3) não foi verificada diferença significativa entre os tratamentos inoculados e a testemunha sem $\mathrm{N}$ mineral. Tanto a população nativa como as cepas inoculantes, exceto a UFLA 3-164, demonstraram alta eficiência na $\mathrm{FBN}$, apresentando valores de $\mathrm{N}$ total nos grãos equivalente à testemunha com $\mathrm{N}$ mineral. Resultados semelhantes foram encontrados por Almeida et al. (2010), avaliando a eficiência das cepas INPA 03 11B (BR 3301), UFLA 0384 (BR 3302) e BR 3267 (SEMIA 6462), no município de Teresina, PI e por Soares et al. (2006), trabalhando com cepas INPA 03 11B
(BR 3301) e UFLA 0384 (BR 3302), em estudo realizado no município de Perdões, MG.

Com relação ao $\mathrm{ANG}$, a cepa INPA 03 11B (BR 3301), foi a única que se assemelhou à testemunha adubada com $\mathrm{N}$ mineral. Outros trabalhos realizados em condições de campo comprovaram boa eficiência da cepa INPA 03 11B (BR 3301) quanto ao acúmulo de $\mathrm{N}$ nos grãos (ALMEIDA et al, 2010; SOARES et al., 2006).

$\mathrm{O}$ rendimento de grãos dos tratamentos inoculados variou de 700,81 a $1.223,41 \mathrm{~kg} \mathrm{ha}^{-1}$ com as cepas UFLA 0384 (BR 3302) e INPA 03 11B (BR 3301), respectivamente. A cepa recomendada pelo MAPA BR 3301 e a cepa em fase de teste UFLA 3-155 mostraram-se superiores às demais cepas, apresentando produtividade semelhante à testemunha nitrogenada, que apresentou rendimento de $1.604,57 \mathrm{~kg} \mathrm{ha}^{-1}$. Esses resultados foram semelhantes aos verificados em ensaios de campo em outras regiões do Brasil. Zilli et al. (2006), em cultivos experimentais em área de cerrado no município de Boa Vista e em área de mata no município de Cantá, RR encontram produtividade de $1.759,00$ e $1.104,00 \mathrm{~kg} \mathrm{ha}^{-1}$ respectivamente quando inoculado a cultivar de feijão-caupi BRS Mazagão com a cepa INPA 03 11B (BR 3301). Sousa (2007) utilizando essa mesma cepa inoculada com a cultivar de

Tabela 2 - Valores médios de matéria seca da parte aérea (MSPA), teor de nitrogênio na parte aérea (TNPA), acúmulo de nitrogênio na parte aérea (ANPA) e eficiência relativa (EFRE) em função de diferentes formas de fornecimento de N na floração (45 dias após semeadura) da cultura do feijão-caupi

\begin{tabular}{lcccc}
\hline \multirow{2}{*}{ Fontes de N } & MSPA & TNPA & ANPA & EFRE \\
\cline { 2 - 5 } & g planta $^{-1}$ & $\%$ & g planta $^{-1}$ & $\%$ \\
\hline Test. S/N & $5,44 \mathrm{~b}$ & $3,45 \mathrm{a}$ & $188,90 \mathrm{~b}$ & $49,52 \mathrm{~b}$ \\
Test. C/N - 70 kg ha-1 & $11,77 \mathrm{a}$ & $3,64 \mathrm{a}$ & $432,07 \mathrm{a}$ & $100,00 \mathrm{a}$ \\
UFLA 3-164 & $6,66 \mathrm{~b}$ & $3,42 \mathrm{a}$ & $228,72 \mathrm{~b}$ & $60,53 \mathrm{~b}$ \\
UFLA 03-84 (BR 3302) & $6,58 \mathrm{~b}$ & $3,40 \mathrm{a}$ & $223,27 \mathrm{~b}$ & $57,59 \mathrm{~b}$ \\
INPA 03 11B (BR 3301) & $7,68 \mathrm{~b}$ & $3,31 \mathrm{a}$ & $256,68 \mathrm{~b}$ & $72,66 \mathrm{~b}$ \\
UFLA 3-155 & $8,36 \mathrm{~b}$ & $3,47 \mathrm{a}$ & $289,98 \mathrm{~b}$ & $75,44 \mathrm{ab}$ \\
BR 3267 & $6,06 \mathrm{~b}$ & $3,45 \mathrm{a}$ & $209,69 \mathrm{~b}$ & $54,70 \mathrm{~b}$ \\
\hline F (Tratamento) & $10,247^{*}$ & $1,458^{*}$ & $8,797 *$ & $8,502^{*}$ \\
Tratamento (GL) & 6 & 6 & 6 & 6 \\
Bloco (GL) & 5 & 5 & 5 & 5 \\
Erro (GL) & 30 & 30 & 30 & 30 \\
QMR & 26,85 & 0,03 & 26946,29 & 1778,98 \\
DMS & 2,95 & 0,38 & 129,36 & 26,37 \\
CV(\%) & 21,55 & 4,74 & 21,18 & 21,52 \\
\hline
\end{tabular}

ns_ não significativo, ${ }^{*}$ Significativo $5 \%$ de probabilidade pelo teste de Tukey, GL $=$ grau de liberdade, QMR $=$ quadrado médio residual, DMS $=$ diferença mínima significativa, $\mathrm{CV}=$ coeficiente de variação. Médias seguidas da mesma letra nas colunas não diferem entre si de acordo com o teste de Tukey a $5 \%$ de probabilidade 
Tabela 3 - Valores médios do número de vagem por planta (NVPL), peso de vagem por planta (PVPL), nitrogênio total nos grãos (TNG), acúmulo de nitrogênio dos grãos (ANG) e rendimento de grãos (RG) (13\% base úmida) da cultura do feijão-caupi

\begin{tabular}{lccccc}
\hline \multirow{2}{*}{ Fonte de N } & NVPL & PVPL & TNG & ANG & RG \\
\cline { 2 - 6 } & número planta ${ }^{-1}$ & $\mathrm{~kg} \mathrm{planta}^{-1}$ & $(\%)$ & $\mathrm{kg} \mathrm{ha}^{-1}$ & $\mathrm{~kg} \mathrm{ha}^{-1}$ \\
\hline Test. S/N & $5,49 \mathrm{~b}$ & $0,01450 \mathrm{abc}$ & $3,62 \mathrm{ab}$ & $34,70 \mathrm{bc}$ & $954,07 \mathrm{ab}$ \\
Test. C/N - 70 kg ha & $8,73 \mathrm{a}$ & $0,01980 \mathrm{a}$ & $3,81 \mathrm{a}$ & $61,28 \mathrm{a}$ & $1604,57 \mathrm{a}$ \\
UFLA 3-164 & $5,37 \mathrm{~b}$ & $0,01280 \mathrm{bc}$ & $3,48 \mathrm{~b}$ & $26,08 \mathrm{bc}$ & $747,74 \mathrm{~b}$ \\
UFLA 03-84 (BR 3302) & $5,35 \mathrm{~b}$ & $0,01386 \mathrm{bc}$ & $3,55 \mathrm{ab}$ & $24,83 \mathrm{c}$ & $700,81 \mathrm{~b}$ \\
INPA 03 11B (BR 3301) & $7,09 \mathrm{ab}$ & $0,01540 \mathrm{abc}$ & $3,60 \mathrm{ab}$ & $44,21 \mathrm{ab}$ & $1223,41 \mathrm{ab}$ \\
UFLA 3-155 & $7,31 \mathrm{ab}$ & $0,01640 \mathrm{ab}$ & $3,60 \mathrm{ab}$ & $36,65 \mathrm{bc}$ & $1016,27 \mathrm{ab}$ \\
BR 3267 & $5,01 \mathrm{~b}$ & $0,01080 \mathrm{c}$ & $3,65 \mathrm{ab}$ & $26,47 \mathrm{bc}$ & $722,49 \mathrm{~b}$ \\
\hline F (Tratamento) & $4,803 *$ & $5,503 *$ & $1,272 *$ & $10,028 *$ & $5,002 *$ \\
Tratamento (GL) & 6 & 6 & 6 & 6 & 6 \\
Bloco (GL) & 5 & 5 & 5 & 5 & 30 \\
Erro (GL) & 30 & 30 & 30 & 42,87 & 5 \\
QMR & 11,62 & 48,86 & 0,03 & 16,41 & 30 \\
DMS & 2,83 & 5,53 & 0,25 & 27,79 & 162,32 \\
CV (\%) & 24,54 & 20,53 & 4,31 & 11,38 \\
\hline
\end{tabular}

ns_ não significativo, "Significativo a 5\% de probabilidade pelo teste de Tukey, GL = grau de liberdade, QMR $=$ quadrado médio residual, DMS = diferença mínima significativa, $\mathrm{CV}=$ coeficiente de variação. Médias seguidas da mesma letra nas colunas não diferem entre si de acordo com o teste de Tukey a $5 \%$ de probabilidade

feijão caupi BR 17 Gurguéia obteve produtividade de $1.025,78 \mathrm{~kg} \mathrm{ha}^{-1}$ em cultivo experimental no município de Confresa, MT. Esses resultados e de outros trabalhos (ALMEIDA et al., 2010; LACERDA et al., 2004; SOARES et al., 2006) mostraram a eficiência simbiótica da cepa INPA 03 11B (BR 3301) quanto ao rendimento de grãos, sendo este mais um trabalho que indica sua eficiência em condições edafo-climáticas diversas daquelas nas quais esta cepa foi testada até o momento. Ressalta se ainda que as produtividades obtidas neste trabalho foram bastante superiores (mais de $200 \%$ ) às produtividades encontradas no estado do Piauí (IBGE, 2006).

A cepa UFLA 3-155 apresentou resultado satisfatório de RG na primeira avaliação realizada em campo, podendo também ser testada em outras regiões brasileiras para verificação de sua capacidade competitiva e de eficiência simbiótica.

\section{Conclusões}

1. A inoculação do feijão-caupi com a nova cepa em fase de teste (UFLA 3-155) proporcionou rendimento de grãos estatisticamente igual à cepa INPA $0311 \mathrm{~B}$ (BR 3301) podendo também ser testada em outras regiões brasileiras para verificação de sua capacidade competitiva e de eficiência simbiótica;

2. As inoculações das sementes de feijão-caupi com as cepas de bactérias diazotróficas INPA 03 11B (BR 3301) e UFLA 3-155 resultaram em rendimento de grãos equivalente a testemunha adubada com nitrogênio mineral e superior às médias do estado do Piauí.

\section{Agradecimentos}

Os autores expressam seus agradecimentos ao Conselho Nacional de Desenvolvimento Científico e Tecnológico (CNPq), pelo auxílio financeiro concedido para a realização do trabalho e pelas bolsas de pesquisa cedidas aos estudantes e pesquisador.

\section{Referências}

ALMEIDA, A. L. G. et al. Produtividade do feijão-caupi cv BR 17 Gurguéia inoculado com bactérias diazotróficas simbióticas no Piauí. Agrária, v. 05, n. 03, p. 364-369, 2010.

ANDRADE, D. et al. Effects of liming and legume/cereal cropping on populations of indigenous rhizobia in an acid Brazilian Oxisol. Soil Biology and Biochemistry, v. 34, p. 477- 485, 2002. 
BERGENSEN, F. J. et al. Studies of natural populations and mutants in the improvement of legume inoculants. Plant and Soil, v. 46, p. 3-16, 1971. Supplement, 1.

DEPRET, G. et al. Long-term effects of crop management on Rhizobium leguminosarum biovar viciae populations. FEMS Microbiology Ecology, v. 51, n. 01, p. 87-97, 2004.

FERREIRA, D. F. Análises estatísticas por meio do Sisvar para Windows 4.0. In: REUNIÃO ANUAL BRASILEIRA DA SOCIEDADE INTERNACIONAL DE BIOMETRIA, 45., São Carlos. Anais... São Carlos: Universidade Federal de São Carlos, 2000. p. 255-258.

FERREIRA, M. C. et al. Tillage method and crop rotation effects on the population sizes and diversity of bradyrhizobia nodulating soybean. Soil Biology and Biochemistry, v. 32, p. $627-637,2000$.

FERREIRA, P. A. A. et al. Inoculação com cepas de rizóbio na cultura do feijoeiro. Ciência Rural, v. 39, n. 07, p. 2210$2212,2009$.

FRANCO, M.C. et al. Nodulação em cultivares de feijão dos conjuntos andinos e meso-americano. Pesquisa Agropecuária Brasileira, v. 37, n. 08, p. 1145-1159, 2002.

FREIRE FILHO, F. R. et al. BR 17 Gurguéia. Embrapa Meio Norte, 2 p. Disponível em: <http://www.cpamn.embrapa.br/ publicacoes/folders/2008/br17_gurgueia.pdf $>$. Acesso em: 10 dez. 2008

FREIRE FILHO, F. R. et al. Caracterização de pólos de produção da cultura de feijão-caupi no Estado o Piauí. Teresina, PI. Embrapa Meio Norte, 2007. 28 p. (Documento, 100).

GUALTER, R. M. R et al. Inoculação e adubação mineral em feijão-caupi: efeitos na nodualçao, crescimento e produtividade. Scientia Agraria, v. 09, n. 04, p. 469-474, 2008

HUNGRIA, M.; VARGAS, M. A. Environmental factors affecting $\mathrm{N}_{2}$ fixation in grain legumes in the tropics, with emphasis on Brasil. Field Crops Research, v. 65, p. 151-164, 2000.

IBGE: Levantamento sistemático da produção agrícola: relatório geral: culturas temporárias da região nordeste. Disponível em: $\quad<$ http://www.ibge.gov.br/home/estatistica/indicadores/ agropecuaria/Ispa/defalt.shtm>. Acesso em: 18 . 2006.

JESUS, E. C. et al. Changes in land use alters the structure of bacterial communities in Western Amazon soils. The ISME Journal, v. 03, p. 1004-1011, 2009.

LACERDA, A. M. et al. Efeito de cepas de rizóbio sobre a nodulação e produtividade do feijão caupi. Revista Ceres, v. 51, n. 293, p. 67-82, 2004.

LIAO, C. F. H. Devarda's allow methods for total nitrogen determination. Soil Science Society of America Journal, v. 45, p. $852-855,1981$.

LIMA, A. S. et al. Diversidade fenotípica e eficiência simbiótica de estirpes de Bradyrhizobium spp. de solos da Amazônia. Pesquisa Agropecuária Brasileira, v. 40, n. 11, p. 1095-1104, 2005.
LIMA, A. S. et al. Nitrogen-fixing bacteria communities occurring in soils under different uses in the Western Amazon region as indicated by nodulation of siratro (Macroptilium atropurpureum). Plant and Soil, v. 319, p. 127-145, 2009.

MALAVOLTA, E. et al. Avaliação do estado nutricional das plantas. 2. ed. Piracicaba: Potafos, 1997. 319 p.

MARTINS, L. M. et al. Contribution of biological nitrogen fixation to cowpea: a strategy for improving grain yield in the semi-arid region of Brazil. Biology and Fertility of Soils, v. 38, n. 06, p. 333-339, 2003.

MELLONI, R. et al. Eficiência e diversidade fenotípica de bactérias diazotróficas que nodulam caupi [Vigna unguiculata (L.) Walp] e feijoeiro (Phaseolus vulgaris L.) em solos de mineração de bauxita em reabilitação. Revista Brasileira de Ciência do Solo, v. 30, p. 235-246, 2006.

BRASIL. Ministério da Agricultura, Pecuáriae Abastecimento. Instrução normativa DAS art. $2^{\circ}$. do decreto ${ }^{0.5741}$ de 30 de março de 2006. Disponível em: $<$ http://www.agricultura. gov.br>. Acesso em: 2010.

MOTTA, J. S. Diversidade fenotípica e eficiência simbiótica de cepas de Bradyrhizobium sp. isoladas de áreas de mineração de bauxita reabilitadas. 2002. 43 f. Dissertação (Mestrado em Solos e Nutrição de Plantas) - Universidade Federal de Lavras, Lavras.

RUMJANEK, N. G. et al. Feijão-caupi tem nova estirpe de rizóbio, BR 3267, recomendada como inoculante. Seropédica: Embrapa Agrobiologia, 2006. 16 p. (Embrapa Agrobiologia, Boletim de Pesquisa e Desenvolvimento, 15).

SANTOS, L. C. et al. População de bactérias e fungos do solo contaminado com cobre nas minas do Camaquã, RS, Brasil. Ciência e Natura, v. 29, n. 02, p. 105-114, 2007.

SOARES, A. L. L. et al. Eficiência agronômica de rizóbios selecionados e diversidade de populações nativas nodulíferas em Perdões (MG). I - Caupi. Revista Brasileira de Ciência do Solo, v. 30, p. 795-802, 2006.

SOUSA, P. M. Potencial do uso da inoculação com bactérias fixadoras de nitrogênio: Alternativa para aumentar a produtividade do feijão-caupi na agricultura familiar de Confresa, Mato Grosso. 2007. 111 f Dissertação (Mestrado em Microbiologia Agrícola) - Universidade Federal de Lavras, Lavras.

VIEIRA, N. M. B. et al. Comportamento dos genótipos de feijoeiro em relação à adubação com nitrogênio mineral e inoculação com rizóbio. Agropecuária Catarinense, v. 18, n. 01, p. $57-61,2005$

XAVIER, G. R. et al. Especificidade simbiótica entre rizóbios e acessos de feijão-caupi de diferentes nacionalidades. Caatinga, v. 19, n. 01, p. 25-33, 2006.

ZILLI, J. E. et al. Avaliação de cepas de rizóbio para a cultura do feijão-caupi em Roraima. Boa Vista: Embrapa Roraima, 2006. 8p. (Embrapa Roraima. Comunicado Técnico, 01). 